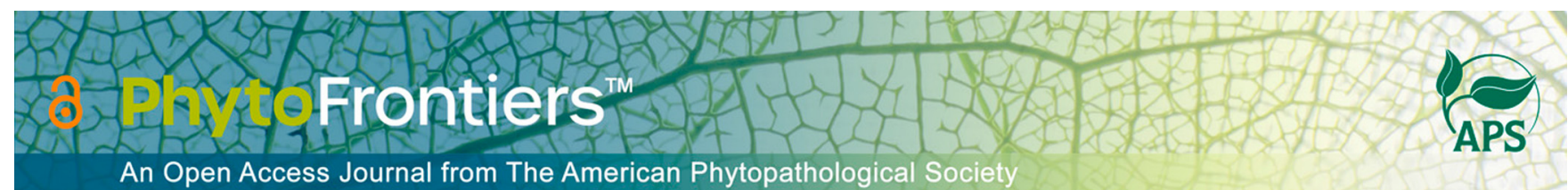

\title{
Research
}

\section{Vibrio gazogenes Inhibits Aflatoxin Production Through Downregulation of Aflatoxin Biosynthetic Genes in Aspergillus flavus}

\author{
Shyam L. Kandel ${ }^{1}$ (D) | Rubaiya Jesmin ${ }^{2}$ | Brian M. Mack ${ }^{1}$ | Rajtilak Majumdar ${ }^{1}$ | Matthew K. Gilbert ${ }^{1}$ | \\ Jeffrey W. Cary $^{1,+}$ | Matthew D. Lebar ${ }^{1}$ | Phani M. Gummadidala ${ }^{3}$ | Ana M. Calvo ${ }^{4}$ | \\ Kanniah Rajasekaran ${ }^{1}$ | Anindya Chanda ${ }^{2,+}$ |
}

1 USDA-ARS, Food and Feed Safety Research Unit, New Orleans, LA 70124

${ }^{2}$ Mycologics LLC, Durham, NC 27709

${ }^{3}$ University of North Carolina School of Medicine, Chapel Hill, NC 27599

${ }^{4}$ Department of Biological Sciences, Northern Illinois University, DeKalb, IL 60115

\section{† Corresponding authors: J. W. Cary; jeff.cary@usda.gov, and A. Chanda chanda@mycologics.net}

Accepted for publication 13 January 2022.

Current address for R. Majumdar: Northwest Irrigation and Soils Research, United States Department of Agriculture, Kimberly, ID 83341.

Current address for S. L. Kandel: USDA-ARS, Sugarbeet and Potato Research Unit, Fargo, ND 58102 .

Mention of trade names or commercial products in this publication is solely for the purpose of providing specific information and does not imply recommendation or endorsement by the United States Department of Agriculture. USDA is an equal opportunity provider and employer.

\section{Funding}

This research was partially funded through the USDA-ARS non-assistance collaborative agreement \#58-6054-5-031 with the University of South Carolina.

$e$-Xtra: Supplementary material is available online.

The author(s) declare no conflict of interest.

\section{Abstract}

Aspergillus flavus is an opportunistic pathogen of oilseed crops such as maize peanut, cottonseed, and tree nuts and produces carcinogenic secondary metabolites known as aflatoxins during seed colonization. Aflatoxin contamination not only reduces the value of the produce but is also a health hazard to humans and animals. Previously, we observed inhibition of $A$. flavus aflatoxin biosynthesis on exposure to the marine bacterium Vibrio gazogenes $(\mathrm{Vg})$. In this study, we used RNA sequencing to examine the transcriptional profiles of $A$. flavus treated with both live and heat-inactivated dead $V g$ and control samples. Fungal biomass, total accumulated aflatoxins, and expression profiles of genes constituting secondary metabolite biosynthetic gene clusters were determined at 24,30 , and $40 \mathrm{~h}$ after treatment. Statistically significant reductions in total aflatoxins were detected in Vg-treated samples as compared with control samples at $40 \mathrm{~h}$. However, no statistical difference in fungal biomass was observed on these treatments. The $V g$ treatments were most effective on aflatoxin biosynthesis, as was reflected in significant downregulation of most genes in the aflatoxin gene cluster, including the aflatoxin pathway regulator gene, afIR. Along with aflatoxin genes, we also observed significant downregulation in some other secondary metabolite gene clusters, including cyclopiazonic acid and aflavarin, suggesting that the treatment could inhibit other secondary metabolites as well. Finally, a weighted gene correlation network analysis identified an upregulation of 10 genes that were most strongly associated with $\mathrm{Vg}$-dependent aflatoxin inhibition and provide a novel starting point in understanding the mechanisms that result in this phenomenon.

Keywords: aflatoxin, Aspergillus flavus, prodigiosin, RNA-seq, secondary metabolism, Vibrio gazogenes 
Aspergillus flavus is an opportunistic plant pathogen that infects fatty acid-rich seeds of maize, peanut, cottonseed, and tree nuts. Toxigenic strains of A. flavus produce carcinogenic mycotoxins known as aflatoxins in addition to other toxic secondary metabolites such as cyclopiazonic acid and aflatrem (Cary et al. 2018; Nicholson et al. 2009; Seshime et al. 2009; Uka et al. 2020). Aflatoxin is classified as a Group-1 carcinogen by the International Agency for Research on Cancer (IARC 1993). Consumption of aflatoxin-contaminated foods can cause aflatoxicosis, liver cancer, immunosuppression, and growth retardation in children (Hyde et al. 2018; Williams et al. 2004). The US Food and Drug Administration sets maximum limits of $20 \mathrm{ppb}$ in commodities for human consumption and $300 \mathrm{ppb}$ for animal feeds. Aflatoxin contamination is a serious problem in tropical and subtropical regions worldwide, including the United States, where climatic conditions such as drought and high temperatures are more conducive to outbreaks (Nelson 2016; Ojiambo et al. 2018; Smith et al. 2019; WHO 2018). It is estimated that nearly $25 \%$ of the world's food crops are destroyed each year due to aflatoxin contamination (WHO 2018) and as many as 4.5 billion people worldwide are at risk of dietary exposure to aflatoxins (Drott et al. 2021).

In the United States, maize is a major agricultural crop, producing more than 350 million metric tons every year with an annual value of about $\$ 50$ billion (USDA-NASS 2021). In maize, A. flavus infects kernels causing ear rot disease and subsequently produces various toxic compounds, especially aflatoxins, that accumulate in the infected kernels. Aflatoxin accumulated in maize grains is persistent in nature and costly to eliminate through processing (Pickova et al. 2021). Although the adverse economic and health impacts of aflatoxin contamination are well documented, an effective and sustainable aflatoxin management method has yet to be developed. Use of cultural practices that support environmental conditions that are nonconducive to fungal infection and aflatoxin production, application of biocontrol non-aflatoxigenic strains that can outcompete aflatoxigenic strains in the field, and breeding for host plant resistance are commonly used techniques to minimize preharvest fungal infection and aflatoxin accumulation in maize. Preharvest aflatoxin management using resistant maize varieties is considered the most economical and practical approach. Several breeding lines and germplasms have been developed and evaluated for resistance to A. flavus infection and aflatoxin production (Brown et al. 2013; Smith et al. 2019). However, inheritance of complex host resistance traits and high genotype $\times$ environment interactions create a major roadblock in developing hybrid maize cultivars resistant to A. flavus infection and aflatoxin contamination. Most of the resistant lines identified to date are agronomically inferior and are not ideal candidates to develop hybrids. Therefore, developing effective management strategies remains crucial to minimize aflatoxin contamination in maize and food items based on maize grains.

Exploring novel aflatoxin mitigation strategies would be helpful to support and improve upon the efficacy of control strategies already being utilized. Microbe-microbe interactions have been utilized to develop novel crop protection strategies for various plant pathogens. Antimicrobial compounds of bacterial origin, polyketides, lipopeptides, hydrolytic enzymes, siderophores, and so on can inhibit hyphae formation, hydrolyze the fungal cell wall, and interfere with the permeability of the cell membrane and acquisition of nutrient resources in fungal plant pathogens (Chalivendra and Ham 2019; Legein et al. 2020; Veliz et al. 2017). Bacillus strains produce diverse arrays of antimicrobials that were found to be effective in minimizing infection from Fusarium spp. and mycotoxin accumulation in wheat and maize (Alberts et al. 2016; Gong et al. 2015; Palazzini et al. 2016). Studies based on in- teractions between A. flavus and associated antagonistic microbes demonstrated significant reductions in A. flavus growth and aflatoxin biosynthesis under in-vitro conditions. Various Bacillus species showed antagonistic activity against $A$. flavus and A. parasiticus growth, as well as degradation of aflatoxins (Chalivendra et al. 2018; Rao et al. 2017; Shu et al. 2018; Xia et al. 2017). Other bacterial strains including Pantoea sp., Lysinibacillus fusiformis, Sporosarcina sp., and Staphylococcus warneri also displayed the ability to degrade aflatoxins in vitro (Adebo et al. 2016; Xie et al. 2019). However, field application of bacterial biocontrol formulations had limited success, probably due to environmental variables and other confounding factors. B. subtilis and Pseudomonas fluorescens strains were shown to be capable of inhibiting the expression of regulatory genes such as $a f D$ and $a f l R$ of the aflatoxin gene cluster (Al-Saad et al. 2016). Furthermore, B. megaterium and Wickerhamomyces anomalus inhibited A. flavus growth and repressed expression of several aflatoxin biosynthetic genes when both organisms were co-cultivated on a nutrient medium (Hua et al. 2019; Kong et al. 2014).

A previous study suggested that the marine bacterium Vibrio gazogenes $(V g)$ can inhibit aflatoxin biosynthesis (Gummadidala 2018; Gummadidala et al. 2016). Vibrio gazogenes is a nonpathogenic, gram-negative bacterium originally recovered from an estuarine marine environment. This bacterium produces antimicrobial compounds including magnesidin A, prodigiosins, and cycloprodigiosins (Gummadidala et al. 2016). In response to aflatoxin, $V g$ produced aflatoxin response metabolites that inhibited aflatoxin biosynthesis in A. parasiticus (Gummadidala et al. 2016). Previous studies suggested that directly applying $V g$ (either live or dead cells) to an A. flavus culture reduced aflatoxins by more than $95 \%$ (Gummadidala 2018; Jesmin 2020). The effect was associated with uptake and internalization of bacterial components by fungal hyphae. Currently, the molecular mechanisms associated with $V g$-dependent aflatoxin inhibition remain unknown. Hence, to obtain an initial insight on the genes associated with this phenomenon, an RNA sequencing (RNA-seq) study was conducted to identify A. flavus genes that showed significant differences in expression upon treatment with live or dead $V g$ cells.

\section{MATERIALS AND METHODS}

\section{Microbial strains and culture conditions}

Aspergillus flavus (NRRL 3357) and Vibrio gazogenes (ATCC 43942) (denoted here as $V g$ ) were used as the fungal and bacterial strain, respectively. NRRL 3357 is a type of A. flavus strain that produces aflatoxins $\mathrm{B}_{1}$ and $\mathrm{B}_{2}$, whereas $V g$ ATCC 43942 is a nonpathogenic marine bacterium that produces the metabolite prodigiosin. A. flavus spore stocks were prepared by growth of the fungus on potato dextrose agar plates at $29^{\circ} \mathrm{C}$ for 7 days, whereas $V g$ was incubated on Difco Marine Broth 2216 (BD Biosciences, Sparks, MD) at $28^{\circ} \mathrm{C}$ under continuous shaking with $190 \mathrm{rpm}$ for $24 \mathrm{~h}$ before harvesting of bacterial cells. Both live $V g$ and heat-inactivated $V g$ (denoted here as dead $V g$ ) cells were used for treating $A$. flavus cultures. For live $V g$ treatments, a 24-h-old $V g$ culture was centrifuged at $4,000 \times g$ for $15 \mathrm{~min}$ at room temperature to pellet bacterial cells. Bacterial pellets were resuspended in $1 \mathrm{ml}$ of yeast extract sucrose (YES) (6\% sucrose, $2 \%$ yeast extract, $\mathrm{pH}$ 5.8) medium (approximately $1.6 \times 10^{7}$ bacterial cells) prior to addition to $100 \mathrm{ml}$ of YES broth for live $V g$ treatments. For dead $V g$ treatments, bacterial pellets resuspended in $1 \mathrm{ml}$ of YES medium were heat-inactivated by incubation at $100^{\circ} \mathrm{C}$ for $10 \mathrm{~min}$, a procedure that was established previously (Gummadidala 2018), in which it was determined via streak plating that the 
process was able to render all $V g$ cells nonviable. A. flavus spores $\left(10^{4}\right.$ spores $\left./ \mathrm{ml}\right)$ were inoculated together with live and dead $V g$ in $100 \mathrm{ml}$ of YES liquid medium at $30^{\circ} \mathrm{C}$ with agitation at $150 \mathrm{rpm}$ in the dark for 24, 30, and $40 \mathrm{~h}$. Control samples consisted of fungal culture without added $V g$ cells. Three biological replicates from live, dead, and untreated fungal control samples were collected at each time point for fungal biomass and aflatoxin measurements and RNA extraction.

\section{Fungal biomass and aflatoxin measurements}

For fungal biomass, culture samples were filtered through Miracloth (Millipore, Billerica, MA) to collect fungal mycelia. The dry weight of mycelial biomass was recorded after drying in an oven at $80^{\circ} \mathrm{C}$ for $6 \mathrm{~h}$. A chloroform-methanol extraction protocol was used to recover the aflatoxin as previously described (Kenne et al. 2018). Total aflatoxin ( $\left.B_{1}+B_{2}\right)$ was measured using ELISA and HPLC procedures as described in Gummadidala (2018). A one-way analysis of variance (ANOVA) in R (R Core Team 2020) was used to compare the mean aflatoxin and mycelial weight measurements between the three treatments (live and dead $V g$ and untreated fungi) within each time point. ANOVA tests having a $P$ value less than 0.05 were followed by a Tukey's honest significant difference post hoc test to confirm where the differences occurred between treatments.

\section{RNA extraction and library preparation}

Total RNA was extracted from the $V g$-treated and untreated mycelial samples harvested at 24,30 , and $40 \mathrm{~h}$. Total RNA was extracted using the TRIzol-based (Sigma, Carlsbad, CA) method following the manufacturer's protocol. RNA samples were purified within $24 \mathrm{~h}$ of extraction using the Qiagen RNEasy kit's RNA Cleanup protocol (Qiagen, Valencia, CA), and stored at $-80^{\circ} \mathrm{C}$. The concentration and purity of all RNA samples were verified by a NanoDrop 2000 Spectrophotometer (Thermo-Fisher Scientific, Waltham, MA). Total RNA was then utilized to generate cDNA libraries using an iScript cDNA Synthesis Kit (BioRad Laboratories, Hercules, CA) as per the manufacturer's instructions. All cDNA samples were stored at $-20^{\circ} \mathrm{C}$ until sequencing. RNA sequencing was conducted in collaboration with Novogene using their standard library preparation and RNA-seq pipeline (Novogene Corporation, Chula Vista, CA).

\section{RNA-seq analysis and processing of RNA-seq data}

Briefly, an Illumina Next Seq 500 platform (Illumina, San Diego, CA) was used to generate 150 -bp paired-end reads. Sequencing reads were trimmed to remove adapters and lowquality sequence using BBDuk (Bushnell 2014). Sequencing reads were mapped to the $A$. flavus NRRL 3357 genome (assembly JCVI-afl1-v2.0, http://www.ncbi.nlm.nih.gov/) using STAR v2.6.1 (Dobin et al. 2013). Total sequence reads, reads after removing adapters and low-quality sequences, and total number of reads mapped in the reference genome were used for downstream analyses (Supplementary Table S1). To make the principal component analysis (PCA) plot, regularized log counts were produced with the DESeq2's rlog function with the option "blind $=$ TRUE" set and used as input to the plotPCA function in DESeq2. Reads mapping to exons were counted using featureCounts v1.6.0 (Liao et al. 2014) followed by differential expression testing with DESeq2 (Love et al. 2014). Genes were removed if they did not have at least 10 reads in 3 or more samples. Differential gene expression analysis was performed to determine the statistical significance of expressed genes in live or heat-killed bacterial treatments to untreated control samples at 24,30 , and $40 \mathrm{~h}$, respectively. Genes were considered differentially expressed if they had an adjusted $P$ value less than 0.05 and a fold change greater than 2. To establish confidence in our RNA-seq data, the transcript levels of a subset of aflatoxin genes ( $a f C$, aflD, aflM, and $a f l R)$ were also measured using the quantitative reverse transcription-PCR (qRT-PCR) assay following the protocol from our previous study (Majumdar et al. 2018). The goal of this qRT-PCR analysis was to ensure that the genes identified as "differentially expressed genes" by RNA-seq under two different conditions or time points indeed showed statistically different levels of transcripts in qRT-PCR analysis. As in our previous study (Majumdar et al. 2018), the A. flavus $\beta$-tubulin gene was used a housekeeping control gene for our experiments.

\section{Functional analyses of differentially expressed genes}

Functional enrichment analysis was conducted to test for enrichment of GO (gene ontology) terms, KEGG (Kyoto Encyclopedia of Genes and Genomes; Kanehisa Laboratories) pathways, InterPro domains, and other annotations within co-expression modules using the enrichment function in the BC3NET R package (de Matos Simoes and Emmert-Streib 2012), which uses a one-sided Fisher's exact test. The $P$ values were corrected for multiple testing using Benjamini and Hochberg's procedure, and adjusted $P$ values were considered enriched if they were less than 0.05 (Benjamini and Hochberg 1995). The bar charts showing GO enrichment results of the differentially expressed genes (DEGs) were made using the top 50 most enriched GO terms and displayed using ggplot2 (Wickham 2016). GO enrichment analysis of DEGs was performed using GOseq (Young et al. 2010). The KEGG enrichment pathway analysis was used to identify DEGs involved in different biochemical pathways (Kanehisa and Goto 2000; Kanehisa et al. 2019). The computation tool KOBAS v3.0 (Xie et al. 2011) was used for the KEGG pathway enrichment analysis.

\section{Gene co-expression network analysis}

Co-expression analysis was conducted using the variancestabilized read counts from DESeq2 as input for the weighted gene correlation network analysis (WGCNA) (Langfelder et al. 2008). The network adjacency matrix was created with the settings "corFnc $=$ 'bicor', type $=$ 'signed hybrid', power $=9$ ". Coexpression module hub genes were identified with the WGCNA function "chooseTopHubInEachModule", but it was modified so that the top 10 genes with the highest connectivity per module were provided instead of just one. A cut height of 0.20 was used to merge similar modules using the "mergeCloseModules" function in WGCNA. Heatmaps were created using the Complex Heatmap $\mathrm{R}$ package ( $\mathrm{Gu}$ et al. 2016). The regularized log-transformed counts from DESeq2 were transformed to the Z-scale using the "scale" function in R and used as input to make the heatmaps.

\section{RESULTS}

An RNA-seq approach was used to understand the temporal gene expression pattern in A. flavus NRRL 3357 during treatments with live or dead $V g$ for 24, 30, and $40 \mathrm{~h}$. Additionally, fungal biomass and aflatoxin accumulation at these time points were determined. No significant differences in fungal dry weight were observed upon $V g$ treatments $(P<0.05)$. No aflatoxin was detected in any samples at $24 \mathrm{~h}$ or in either live or dead $V g$-treated samples at $30 \mathrm{~h}$. A significant reduction in aflatoxin biosynthesis $(P<0.05)$ was detected on either live or dead $V g$ treatments as compared with untreated control samples at $40 \mathrm{~h}$ (Table 1). 
Approximately 1.2 billion RNA-seq reads were generated from all samples using Illumina Next Seq 500. More than $89 \%$ of the reads mapped to at least one position in the A. flavus NRRL 3357 reference genome. Among these mapped reads, 91\% mapped to exon regions, and $9 \%$ mapped to intergenic regions. The overall variability in the gene expression data was summarized using a PCA (Fig. 1). The variance explained by the first and second principal components was $55 \%$ and $13 \%$, respectively. The results indicate distinct transcriptomic variation observed between the control-treated and live/dead Vibrio-treated samples, specifically at the 24 and $30 \mathrm{~h}$ time points. The first principal component separated the samples very well according to time, and the first principal component is correlated with time (Pearson's correlation coefficient of 0.84). The second principal component separated the samples according to $V g$ treatment. The second principal component is correlated with treated versus untreated status (Pearson's correlation coefficient of 0.85 when setting treated with live or dead $V g$ as 0 and untreated as 1). Also of note, the variation observed between the live and dead treatments is a time-dependent transcriptomic response, where the transcriptomic profiles between live and dead $V g$ are similar at early time points tested. There is little variation in the responses between live and dead treatment at the 24-h time point; however, as the treatment time extends to $40 \mathrm{~h}$, the variation between live and dead treatment becomes more pronounced.

Differential gene expression patterns were examined by comparing the expression values between live and dead $V g$ treatments versus untreated control samples at each time point. More A. flavus genes were upregulated on treatment with live $V g$ than with dead $V g$ cells. A total of 223, 806, and 275 fungal genes were significantly differentially upregulated and 337, 828, and 154 were downregulated at 24,30 , and $40 \mathrm{~h}$, respectively, in live bacterial treatments. In dead bacterial treatments, 115,95 , and $24 \mathrm{~A}$. flavus genes were upregulated and 60,121, and 25 were downregulated. Venn diagrams display the numbers of uniquely expressed or overlapping genes in A. flavus in response to either live or dead bacterial treatment (Fig. 2). More genes were uniquely expressed in live than dead bacterial treatments compared with untreated control samples (live versus control compared with dead versus control, Fig. 2A and B). At 40 h, nearly all up- and downregulated genes in dead $V g$ treatment were common to live $V g$ treatment (Fig. 2). As expected, expression of all the aflatoxin genes ( $a f l C$, aflD, aflM, and $a f l R)$ examined by qRT-PCR assay showed significant reduction on $V g$ treatment as compared with

TABLE 1

Effect of Vibrio gazogenes $(\mathrm{Vg})$ treatments on fungal biomass (measured as dry weight) and aflatoxin accumulation ${ }^{\mathrm{Z}}$

\begin{tabular}{|c|c|c|c|c|}
\hline \multirow[b]{2}{*}{ Measurement in Aspergillus flavus } & \multirow[b]{2}{*}{ Treatment } & \multicolumn{3}{|c|}{ Time points } \\
\hline & & $24 \mathrm{~h}$ & $30 \mathrm{~h}$ & $40 \mathrm{~h}$ \\
\hline \multirow[t]{3}{*}{ Dry weight (g) } & Control & $0.06(0.01)$ & $0.36(0.04)$ & $0.61(0.05)$ \\
\hline & Live $V g$ & $0.04(<0.01)$ & $0.30(0.05)$ & $0.43(0.07)$ \\
\hline & Dead $V g$ & $0.05(0.01)$ & $0.27(0.03)$ & $0.45(0.03)$ \\
\hline \multirow[t]{3}{*}{ Aflatoxin (ppb) } & Control & BDL & $7.83(2.20)$ & $44.33 \mathrm{a}(4.10)$ \\
\hline & Live $V g$ & $\mathrm{BDL}$ & BDL & $3.77 \mathrm{~b}(1.63)$ \\
\hline & Dead $V g$ & $\mathrm{BDL}$ & $\mathrm{BDL}$ & $4.60 \mathrm{~b}(1.00)$ \\
\hline
\end{tabular}

${ }^{\mathrm{z}} \mathrm{BDL}=$ below detection limit. Aflatoxin measurements with the same superscript letter are not significantly different $(P<0.05)$ according to Tukey's post hoc test. No statistically significant difference was found when comparing dry weight samples. Numbers in parentheses are standard error of means.

\section{PCA of regularized log2 counts}

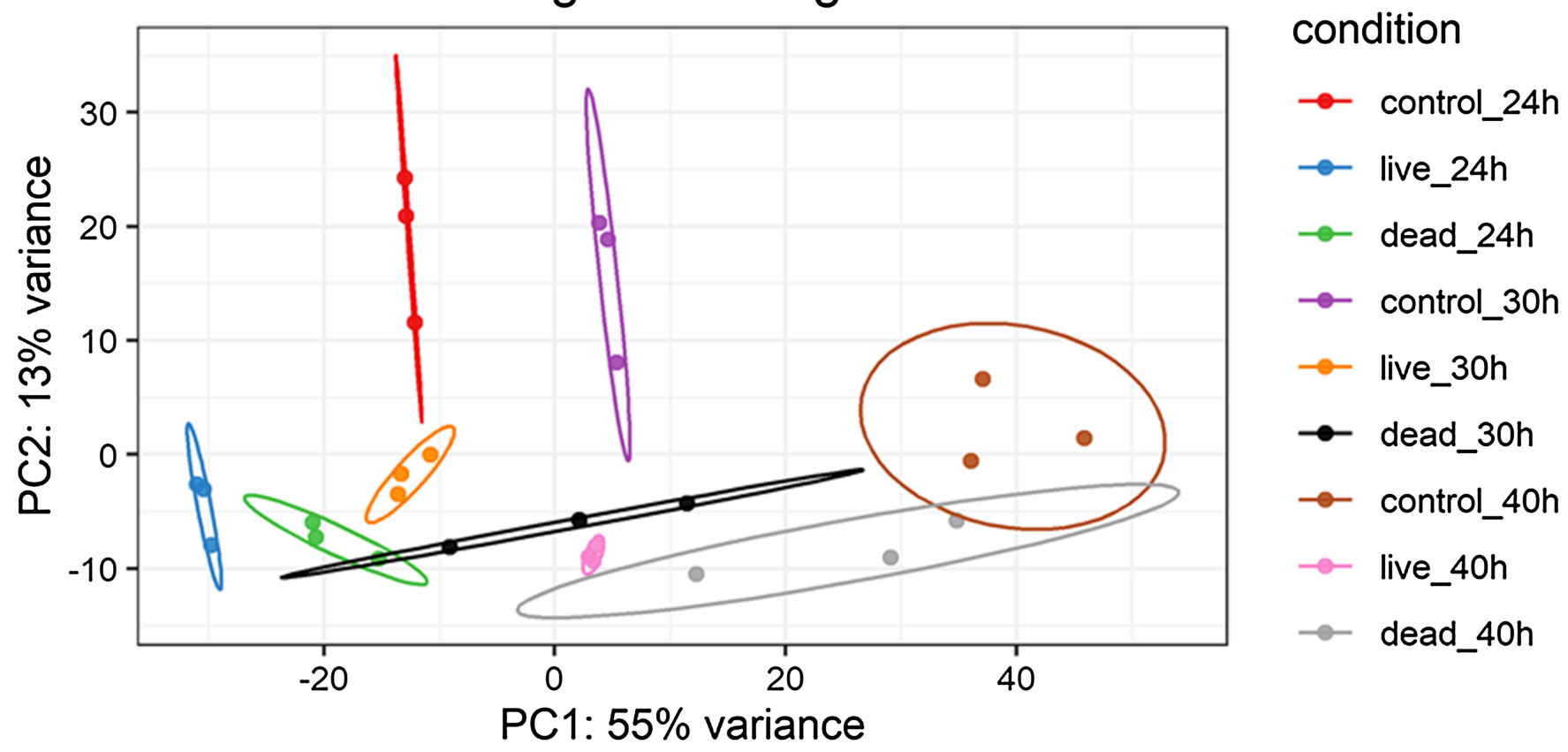

FIGURE 1

Principal component analysis (PCA) of expression values across treatments at 24,30 , and $40 \mathrm{~h}$. Regularized log-transformed counts for each gene were used as input for the PCA. The $95 \%$ confidence ellipses were inserted covering three replicates of each treatment. 
controls, thereby validating our RNA-seq results (see Supplementary Fig. S1).

The weighted gene correlation network analysis was performed using the count data of RNA-seq reads mapped to the A. flavus reference genome. The WGCNA analysis evaluates the pairwise correlation between genes across samples, converts the correlation matrix into a topological overlap map, and then computes a hierarchical clustering tree. A total of 15 modules were identified, each consisting of genes with similar expression patterns. The gene expression profile of each module was
A

$\begin{array}{cc}24 \mathrm{~h} \text { dead } & 24 \mathrm{~h} \text { live } \\ \text { vs } & \text { vs }\end{array}$

$24 \mathrm{~h}$ control $24 \mathrm{~h}$ control

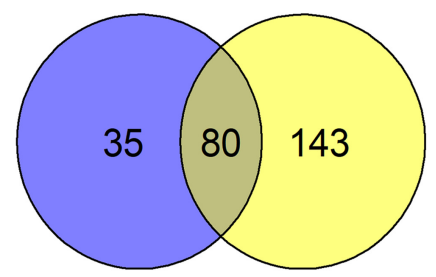

B
$24 \mathrm{~h}$ dead
24h live
vs
vs

$24 \mathrm{~h}$ control $24 \mathrm{~h}$ control

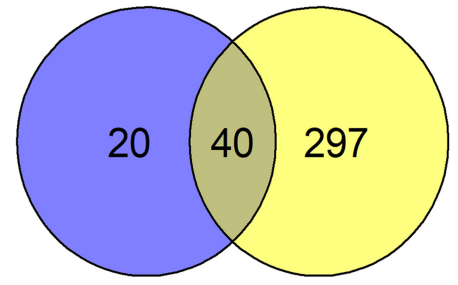

Upregulated DEGs

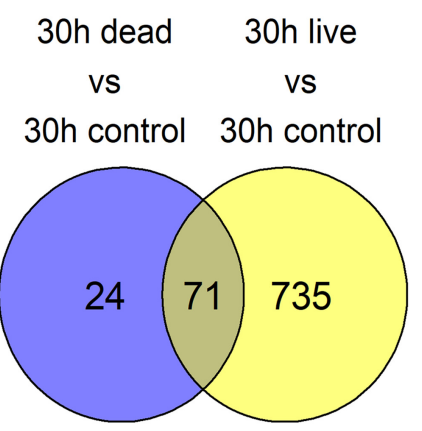

Downregulated DEGs

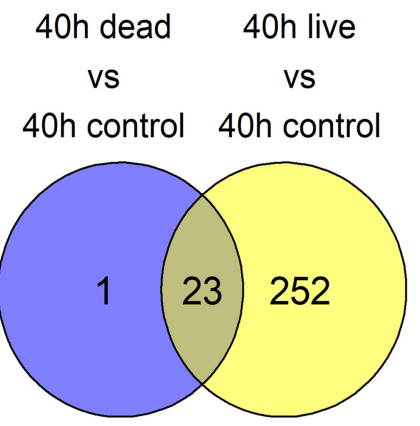
40h dead $\quad$ 40h live
vs
vs

40h control $40 \mathrm{~h}$ control
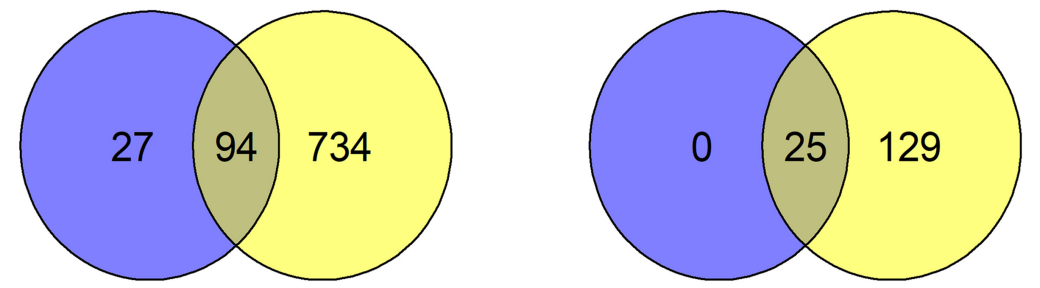

FIGURE 2

Venn diagrams of differentially expressed genes (DEGs) including upregulated and downregulated DEGs during the Vibrio gazogenes $(V g)$ treatments: upregulated $(\mathbf{A})$ and downregulated $(B) D E G s$ (adjusted $P<0.05$ ) in live or dead $V g$ treatments versus untreated control samples at 24,30 , and $40 \mathrm{~h}$.

A

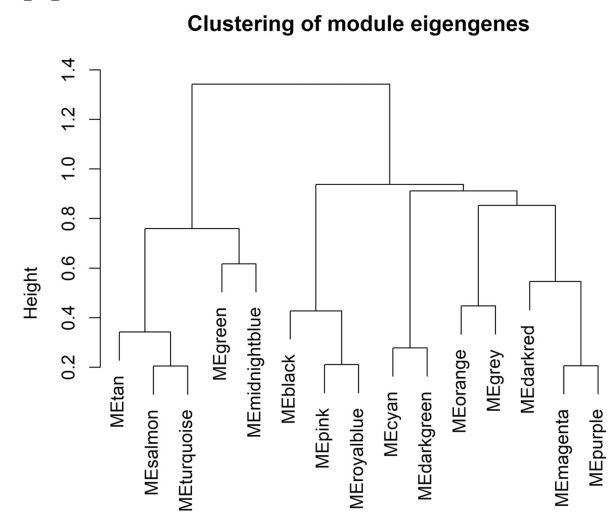

B

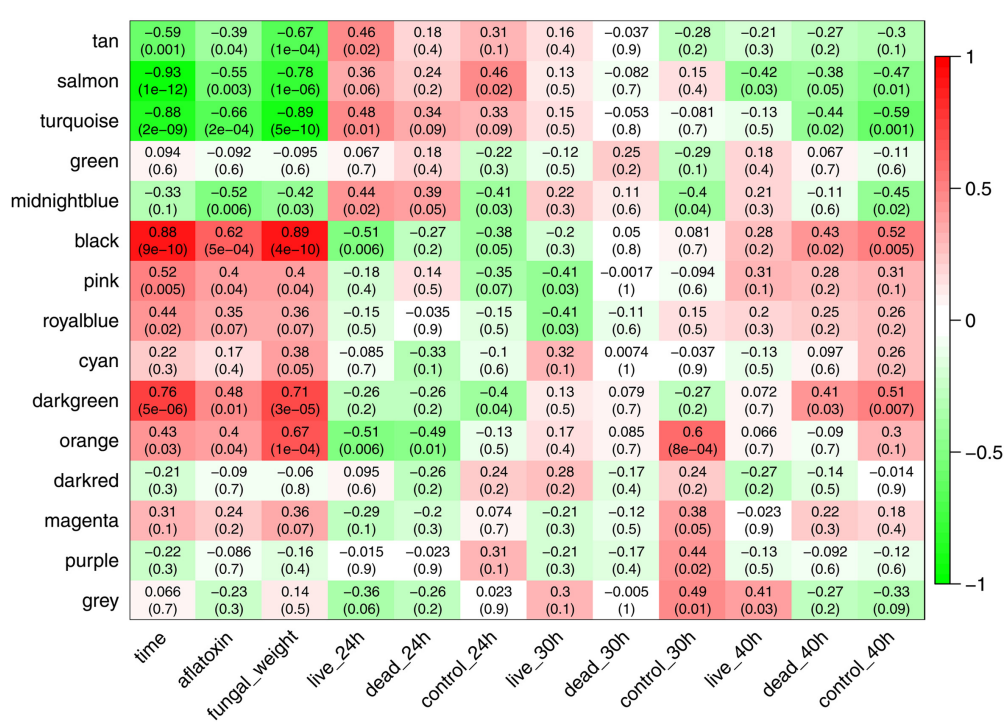

FIGURE 3

Weighted gene correlation network analysis co-expression module eigengenes and module-trait relationships using the variancestabilized read counts from RNA-sequencing samples of Aspergillus flavus. A, Hierarchical clustering of module eigengenes; and B, module-trait relationships identified through correlation analysis. The module-trait relationships are colored based on their relationship; red indicates a strong positive correlation, whereas green is a strong negative correlation. Numbers in parentheses are $P$ values. Traits include time point, aflatoxin amount, fungal dry weight, and treatment variables. 
represented by an eigengene, and eigengenes were clustered according to the co-expression similarity pattern. Hierarchical clustering of eigengenes is displayed as modules (Fig. 3A). Moduletrait relationships with time point, fungal dry weight, and total accumulated aflatoxins of A. flavus, as well as all treatments, including untreated control, live, or dead $V g$ cells at 24,30 , and $40 \mathrm{~h}$, were assessed by correlating each module's eigengene to individual traits. Several modules were positively or negatively correlated with traits (Fig. 3B). The amount of aflatoxin accumulation was a major trait of interest. Modules most significantly correlated with total aflatoxin were selected, and genes from these modules were retrieved based on their intra-modular connectivity. Genes with high connectivity were selected using the co-expression adjacency (expression correlation between genes) and topological overlap (topological similarity) matrices. The gene significance (correlation between gene expression and trait)

\section{TABLE 2}

List of significantly downregulated genes (Padj. $\leq 0.05$, live or dead Vibrio gazogenes versus control) related to secondary metabolite biosynthesis including aflatoxin in Aspergillus flavus

\begin{tabular}{|c|c|c|c|c|}
\hline \multirow[b]{2}{*}{ Gene ID } & \multicolumn{2}{|c|}{$\log _{2}$ fold change } & \multirow[b]{2}{*}{ Putative function } & \multirow[b]{2}{*}{ Secondary metabolites } \\
\hline & Live versus control & Dead versus control & & \\
\hline \multicolumn{5}{|l|}{$24 \mathrm{~h}$} \\
\hline AFLA_002890 & & -1.84 & AMP-binding enzyme family protein & Pyripyropene $^{\mathrm{y}}$ \\
\hline AFLA_002920 & & -2.50 & Flavonoid 3-hydroxylase, putative & Pyripyropene ${ }^{\mathrm{y}}$ \\
\hline AFLA_004440 & & -2.37 & ABC multidrug transporter, putative & Fumiquinazolines $^{\mathrm{y}}$ \\
\hline AFLA_139270 & -1.83 & & aflNa/hypD/hypothetical protein & Aflatoxin \\
\hline AFLA_139340 & -2.21 & & aflS/pathway regulator & Aflatoxin \\
\hline AFLA_139360 & -1.68 & & aflR/apa-2/afl-2/transcription activator & Aflatoxin \\
\hline AFLA_139460 & -1.93 & & MFS multidrug transporter, putative & Cyclopiazonic acid \\
\hline AFLA_139470 & -6.06 & & FAD dependent oxidoreductase, putative & Cyclopiazonic acid \\
\hline AFLA_139480 & -4.55 & & Dimethylallyl tryptophan synthase, putative & Cyclopiazonic acid \\
\hline AFLA_096340 & -1.48 & & Hypothetical protein & Aflatrem \\
\hline \multicolumn{5}{|l|}{$30 \mathrm{~h}^{\mathrm{z}}$} \\
\hline AFLA_108540 & -0.63 & & NADH oxidase, putative & Aflavarin \\
\hline AFLA_108550 & -2.54 & & Polyketide synthase, putative & Aflavarin \\
\hline AFLA_139340 & -2.67 & & aflS/pathway regulator & Aflatoxin \\
\hline AFLA_139360 & -1.88 & & aflR/apa-2/afl-2/transcription activator & Aflatoxin \\
\hline AFLA_139370 & -2.44 & & aflB/fas-1/fatty acid synthase beta subunit & Aflatoxin \\
\hline AFLA_139420 & -1.87 & & aflT/aflT/transmembrane protein & Aflatoxin \\
\hline AFLA_139460 & -2.76 & & MFS multidrug transporter, putative & Cyclopiazonic acid \\
\hline AFLA_139470 & -1.77 & & FAD-dependent oxidoreductase, putative & Cyclopiazonic acid \\
\hline AFLA_139480 & -1.22 & & Dimethylallyl tryptophan synthase, putative & Cyclopiazonic acid \\
\hline AFLA_139490 & -1.54 & & Hybrid PKS/NRPS enzyme, putative & Cyclopiazonic acid \\
\hline AFLA_064330 & -3.32 & & Conserved hypothetical protein & Imizoquins \\
\hline \multicolumn{5}{|l|}{$40 \mathrm{~h}$} \\
\hline AFLA_139150 & -6.51 & -3.50 & aflY/hypA/hypP/hypothetical protein & Aflatoxin \\
\hline AFLA_139160 & -9.75 & -3.27 & aflX/ordB/monooxygenase/oxidase & Aflatoxin \\
\hline AFLA_139170 & -7.85 & -3.51 & aflW/moxY/monooxygenase & Aflatoxin \\
\hline AFLA_139180 & -10.06 & -3.47 & aflV/cypX/cytochrome P450 monooxygenase & Aflatoxin \\
\hline AFLA_139190 & -9.97 & -3.74 & aflK/vbs/VERB synthase & Aflatoxin \\
\hline AFLA_139200 & -8.42 & -3.65 & $\begin{array}{l}\text { aflQ/ordA/ord-1/oxidoreductase/cytochrome P450 } \\
\text { monooxygenase }\end{array}$ & Aflatoxin \\
\hline AFLA_139210 & -10.29 & -3.78 & aflP/omtA/omt-1/O-methyltransferase A & Aflatoxin \\
\hline AFLA_139220 & -10.47 & -3.77 & aflO/omtB/dmtA/O-methyltransferase B & Aflatoxin \\
\hline AFLA_139230 & -7.62 & -3.79 & aflI/avfA/cytochrome P450 monooxygenase & Aflatoxin \\
\hline AFLA_139240 & ns & -3.40 & aflLa/hypB/hypothetical protein & Aflatoxin \\
\hline AFLA_139250 & -10.44 & -3.40 & aflL/verB/desaturase/P450 monooxygenase & Aflatoxin \\
\hline AFLA_139260 & -9.70 & -3.62 & aflG/avnA/ord-1/cytochrome P450 monooxygenase & Aflatoxin \\
\hline AFLA_139270 & -3.83 & -1.79 & aflNa/hypD/hypothetical protein & Aflatoxin \\
\hline AFLA_139280 & -7.54 & -3.51 & aflN/verA/monooxygenase & Aflatoxin \\
\hline AFLA_139290 & ns & -3.11 & aflMa/hypE/hypothetical protein & Aflatoxin \\
\hline AFLA_139300 & -8.90 & -3.86 & aflM/ver-1/dehydrogenase/ketoreductase & Aflatoxin \\
\hline AFLA_139310 & -8.50 & -3.75 & aflE/norA/aad/adh-2/NOR reductase/dehydrogenase & Aflatoxin \\
\hline AFLA_139320 & -8.49 & -3.84 & aflJ/estA/esterase & Aflatoxin \\
\hline AFLA_139330 & -6.69 & -3.61 & aflH/adhA/short chain alcohol dehydrogenase & Aflatoxin \\
\hline AFLA_139340 & -2.67 & ns & aflS/pathway regulator & Aflatoxin \\
\hline AFLA_139360 & -1.30 & ns & aflR/apa-2/afl-2/transcription activator & Aflatoxin \\
\hline AFLA_139370 & -2.02 & ns & aflB/fas-1/fatty acid synthase beta subunit & Aflatoxin \\
\hline AFLA_139390 & -3.28 & -2.65 & aflD/nor-1/reductase & Aflatoxin \\
\hline AFLA_139400 & -3.36 & -2.63 & aflCa/hypC/hypothetical protein & Aflatoxin \\
\hline AFLA_139410 & -2.49 & -2.39 & aflC/pksA/pksL1/polyketide synthase & Aflatoxin \\
\hline AFLA_139420 & -3.14 & ns & aflT/aflT/transmembrane protein & Aflatoxin \\
\hline AFLA_139430 & -2.80 & ns & aflU/cypA/P450 monooxygenase & Aflatoxin \\
\hline AFLA_139440 & -2.72 & ns & aflF/norB/dehydrogenase & Aflatoxin \\
\hline AFLA_139460 & -6.38 & ns & MFS multidrug transporter, putative & Cyclopiazonic acid \\
\hline AFLA_139470 & -1.21 & ns & FAD-dependent oxidoreductase, putative & Cyclopiazonic acid \\
\hline
\end{tabular}

y A. flavus gene showed homology to a gene from Aspergillus spp. using the biosynthetic gene cluster database (https://mibig.secondarymetabolites.org/), but the presence of metabolites was not confirmed in A. flavus. ns = not significant.

$\mathrm{z}$ There were no dead versus control at $30 \mathrm{~h}$. 
for total aflatoxin and module membership (association between gene expression and module eigengene) for turquoise, salmon, midnight blue, black, dark green, and orange modules are shown in Supplementary Figure S2. The expression pattern of genes identified in these modules had strong negative and positive correlations with aflatoxin production and fungal weight (Fig. 3 and Supplementary Figure S2). In these modules, gene significance and module membership have a significant correlation, indicating a crucial role in aflatoxin biosynthesis in A. flavus.

The top 10 genes with the highest connectivity from each module were identified and retrieved as hub genes. Interestingly, all co-expressed hub genes selected in the turquoise module are related to $40 \mathrm{~S} / 60 \mathrm{~S}$ ribosomal proteins, which were mostly repressed at $40 \mathrm{~h}$. The hub genes in the midnight blue module were strongly repressed in all control samples but expressed substantially on live and dead $V g$ treatments (Supplementary Figure S3). Genes involved in activities of cellulolytic enzymes such as cellulase and endoglucanase, fatty acid hydrolysis enzymes such as lipase and enoyl-CoA hydratase/isomerase, and siderophore biosynthesis and transport were identified as hub genes in the midnight blue module and highly significant at $40 \mathrm{~h}$ (live $\mathrm{Vg}$ versus control) (Supplementary Table S2).

We also examined the expression pattern of genes in experimentally characterized secondary metabolite gene clusters; aflatoxin, aflatrem, aflavarin, asparasone A, cyclopiazonic acid, ditryptophenaline, flavunoidine 1 , kojic acid, leporin, piperazine, imizoquins, and ustiloxin B. At 24 and $30 \mathrm{~h}$ time points, a limited number of genes related to aflatoxin biosynthesis were significantly downregulated (live or dead $V g$ versus control). However, most of the aflatoxin biosynthesis pathway-related genes were significantly downregulated in both live and dead $V g$ treatments compared with the control samples at $40 \mathrm{~h}$ (Table 2). Furthermore, some genes in the adjacent cyclopiazonic acid cluster, including AFLA_139460-MFS multidrug transporter, putative, AFLA_139470-FAD-dependent oxidoreductase, and AFLA_139480-tryptophan dimethylallyl transferase, were significantly downregulated only in live $V g$-treated samples across all time points (Table 2). One or two genes involved in aflatrem, aflavarin, and imizoquins were significantly downregulated in live $V g$ treatments at 24 and $30 \mathrm{~h}$ (Table 2). However, no genes related to other experimentally characterized secondary metabolites were found to be significantly differentially expressed. Furthermore, genes related to oxidative stress (atfB, $A P-1)$ or secondary metabolism (veA, laeA, $n s d C$, and $n s d D$ ) were not significantly differentially expressed, except for slight downregulation (log2fold change $\approx-1.2$ ) of gene atfB in live $V g$ versus control treatments at 24 and $30 \mathrm{~h}$ (Supplementary Table S3).

Gene ontology (GO) enrichment analysis was performed using significantly up- and downregulated genes in A. flavus in response to live or dead $V g$ treatments to identify significant GO terms associated with biological processes, cellular components, and molecular functions. In live $V g$ treatments, only the organic heteropentacyclic compound metabolic/biosynthetic process and aflatoxin metabolic/biosynthetic process were enriched GO terms within the downregulated genes, whereas all other enriched GO terms were associated with upregulated genes across all samples (Fig. 4). In dead $V g$ treatment, all significant enriched GO terms were associated with downregulated genes, including biological processes and molecular functions (Fig. 5).

\section{GO term enrichment of DEGs from Live-Vibrio vs Control comparison}

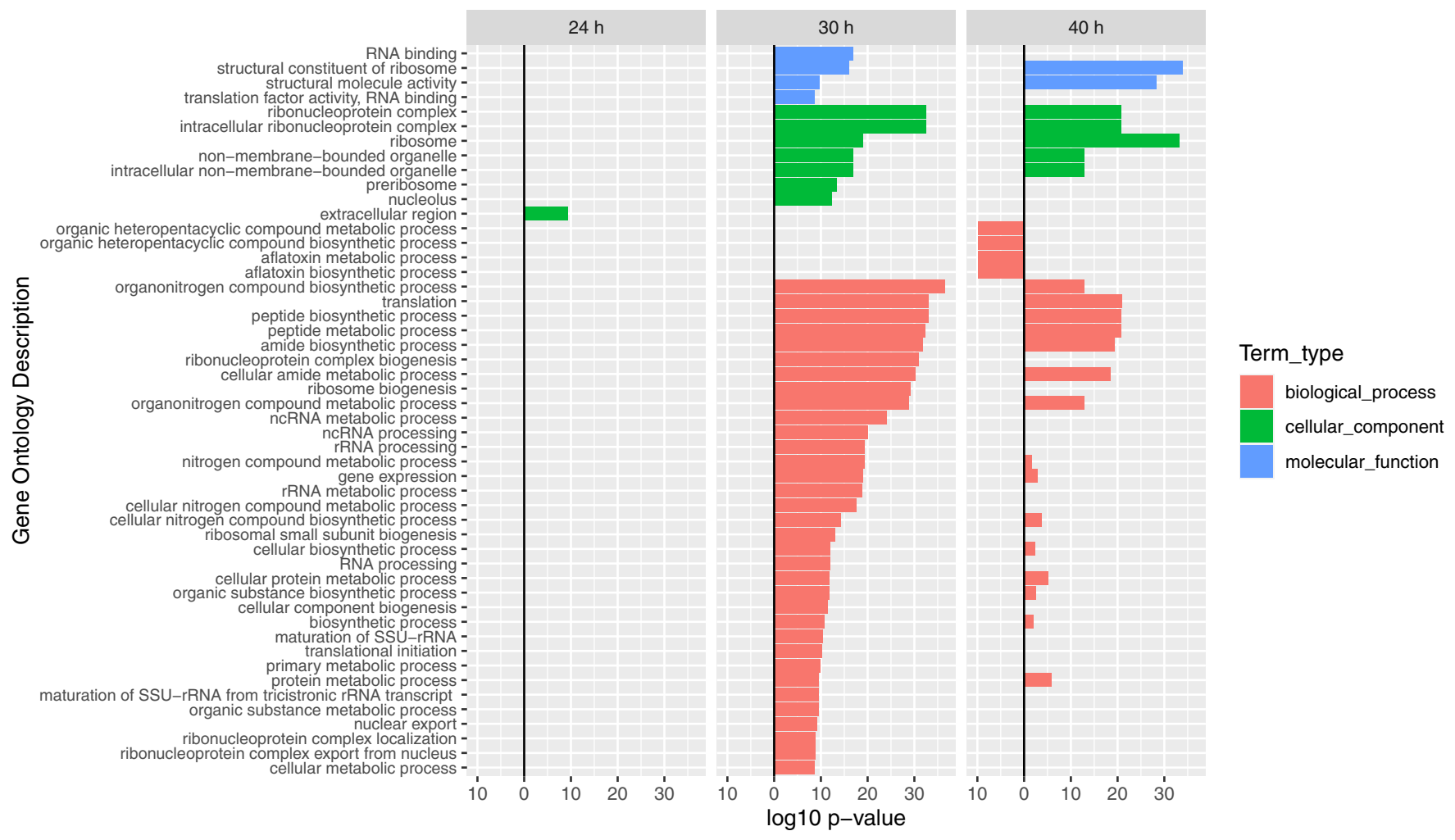

FIGURE 4

Gene ontology (GO) term enrichment of differentially expressed genes in Aspergillus flavus in response to the live Vibrio gazogenes treatment (as compared with control). The absolute log10-adjusted $P$ values are indicated by the length of the bars. GO terms related to biological processes are shown in orange, cellular components in green, and molecular functions in blue. Downregulated genes are to the left of the origin and upregulated to the right. 
The KEGG pathway analysis was performed using A. flavus DEGs identified from the RNA-seq data. Notably, the aflatoxin biosynthesis pathway was the only significant KEGG pathway associated with downregulated genes, whereas all other 19 significant secondary metabolite pathways were associated with upregulated genes (Supplementary Table S4). In the aflatoxin biosynthesis pathway, several genes including aflK, aflQ, aflP, aflO, aflG, aflJ, aflH, aflD, aflCa, and $a f C$, essential to produce aflatoxins, were significantly downregulated at $40 \mathrm{~h}$ (live or dead $\mathrm{Vg}$ versus untreated control samples) (Fig. 6). Interestingly, several upregulated genes during live $V g$ treatments at 30 and $40 \mathrm{~h}$ were found to be associated with ribosome-associated enriched KEGG pathways (Supplementary Table S4).

\section{DISCUSSION}

The ascomycete $A$. flavus can infect and produce carcinogenic aflatoxins in oilseed crops such as maize. As such, identifying a suitable avenue to manage aflatoxin contamination in maize and other oilseed crops is of great importance to improve food safety and minimize economic losses. Although previous studies have suggested that the marine bacterium $V g$ can inhibit aflatoxin biosynthesis in A. flavus (Gummadidala 2018; Jesmin 2020), the molecular factors contributing to this effect are unknown. As the first step to address this knowledge gap, the current study pursued an RNA-seq approach for in silico analysis of gene expression in A. flavus treated with either live or dead $V g$ cells. The gene expression in the treated samples was compared with that of untreated control samples at 24,30 , and $40 \mathrm{~h}$. These are the time points that correspond to the different stages of aflatoxin production under the current growth conditions (Gummadidala 2018). At $24 \mathrm{~h}$, aflatoxin was not detected in the growth medium. At $30 \mathrm{~h}$, aflatoxin accumulation was detected, and at $40 \mathrm{~h}$, aflatoxin production reached peak levels (Gummadidala 2018). The fungal dry weight and aflatoxin measurements observed in this study agreed with our previous observations, which founded the premise of the current study. No statistically significant difference in dry weight was observed upon $V g$ treatment, which suggests that mycelial biomass was not significantly affected. We observed about a $25 \%$ drop in dry weight, which might be reflective of the impacts of $V g$ on colonial architecture (such as polar growth or branching) that will be investigated in our future studies. As observed previously, aflatoxin was inhibited by about $90 \%$ on treatments with both live and dead Vg (Gummadidala 2018; Jesmin 2020).

Among secondary metabolite biosynthesis gene clusters, the aflatoxin biosynthetic cluster was downregulated the most by both live and dead $V g$ treatments (Table 2). Aflatoxin biosynthesis in A. flavus is regulated by the coordination of more than 30 functional genes including monooxygenases (aflG, afl, aflV, aflN, $a f l W, a f l X)$, reductases ( $a f l D$ and $a f l E$ ), dehydrogenases ( $a f l H$ and $a f M$ ), and gene regulators ( $a f l R$ and $a f l S$ ) (Liao et al. 2020; Uka et al. 2020; Yu 2012). At 40 h, 28 and 22 out of 30 genes in the aflatoxin biosynthetic gene cluster were significantly downregulated in the presence of live and dead $V g$ cells, respectively (Table 2). At $30 \mathrm{~h}$, only 4 genes from the aflatoxin biosynthesis pathway were significantly downregulated in the live $V g$ treatment but none in the dead $V g$ treatment. Furthermore, the organic heteropentacyclic compound metabolic/biosynthetic

\section{GO term enrichment of DEGs from Dead-Vibrio vs Control comparison}

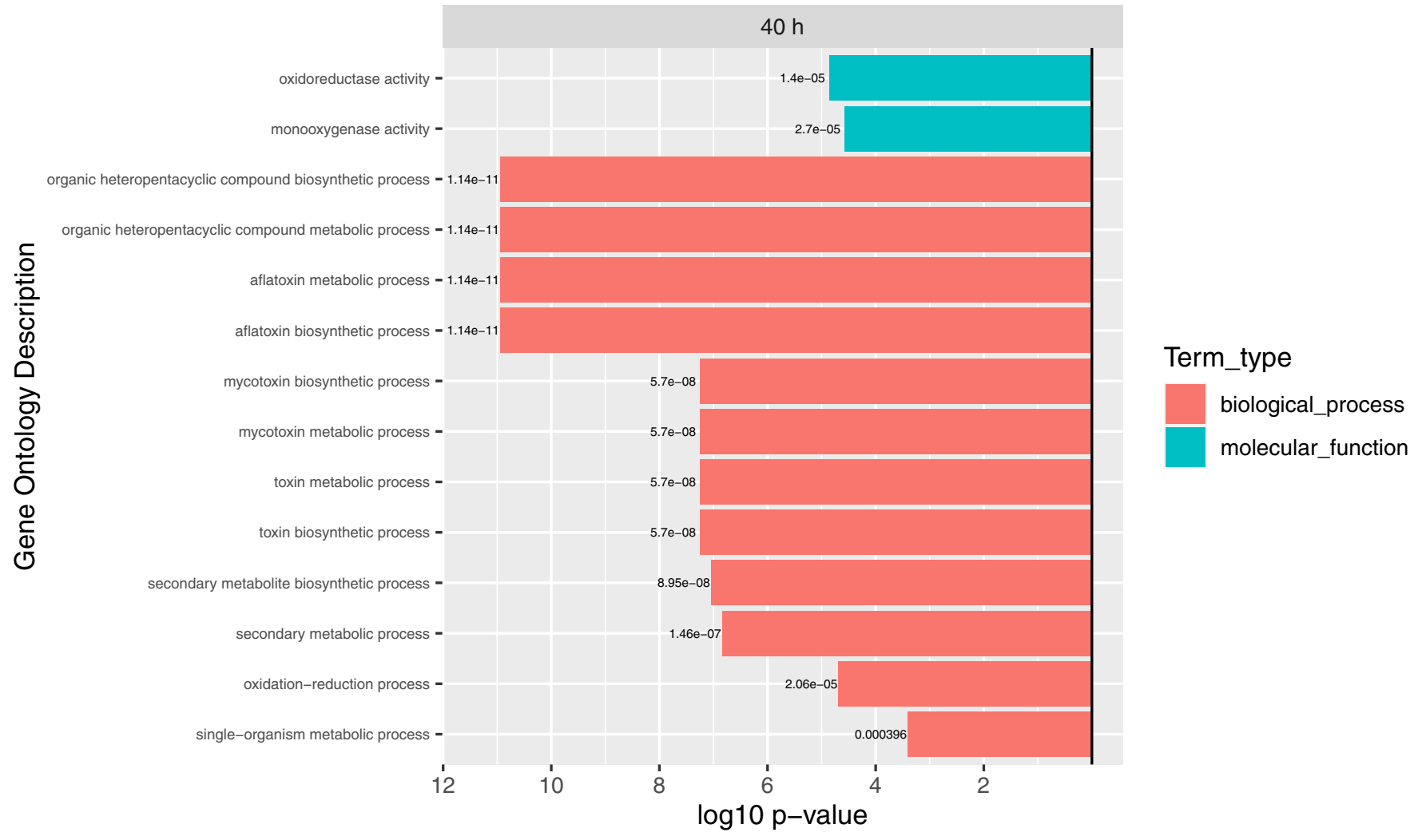

FIGURE 5

Gene ontology (GO) term enrichment of differentially expressed genes (DEGs) in Aspergillus flavus in response to the dead Vibrio gazogenes treatment (as compared with control). The absolute log10-adjusted $P$ values are indicated by the length of the bars. GO terms related to biological processes are shown in orange and molecular functions in blue. Downregulated genes are to the left of the origin and upregulated to the right. 
process and aflatoxin metabolic/biosynthetic process were the most significantly enriched GO terms closely associated with downregulated genes in both $V g$ treatments at $40 \mathrm{~h}$ (Figs. 4 and 5). However, significantly enriched GO terms related to the molecular functions, cellular components, and other biological processes were found to be associated with the upregulated genes at 30 and $40 \mathrm{~h}$ (Fig. 4). The GO term enrichment analysis indicates that the presence of live or dead $V g$ cells selectively inhibits the aflatoxin biosynthetic pathway but no other biochemical process. Additionally, our KEGG pathway enrichment analysis showed that several downregulated genes identified at $40 \mathrm{~h}$ in both live and dead $V g$ treatments were associated with key enzymes essential for the aflatoxin biosynthesis (Fig. 6).

Bacterial strains in marine estuarine environments are often exposed to urban or agricultural effluents (Cavalheiro et al. 2017; Osterholz et al. 2018; Zhang et al. 2019). It is possible that marine Vibrio such as $V g$ have developed effective mechanisms to tolerate or modulate toxic compounds such as aflatoxins present in the environment. $V g$ produces large amounts of the red-pigmented, secondary metabolite called prodigiosin (Allen et al. 1983; Boric et al. 2011; Gummididala et al. 2017), and in our studies, we have consistently used $V g$ cells after they produced prodigiosin, as evident by the red color of the $V g$ cells when added to the fungal growth medium. Given the insolubility of prodigiosin in water, almost all prodigiosin produced by the $V g$ was associated with the $V g$ cells and hence easily visible on $V g$ cells. Because prodigiosin is known for its antifungal activity (Han et al. 2021), it is possible that prodigiosin at least in part contributes to the $V g$-dependent aflatoxin inhibition, which will be investigated in more detail in our follow-up studies. Several other commercially available bacteria-derived aflatoxin inhibitors such as aflastatins and blasticidins have also demonstrated the ability to selectively inhibit the aflatoxin biosynthesis pathway in A. flavus and A. parasiticus (Sakuda 2010; Sakuda et al. 1996, 2000, 2016). For example, aflastatin A was shown to specifically target the biochemical pathway responsible for biosynthesis of polyketide compounds including aflatoxins. Another bacterial (Streptomyces sp.) metabolite, dioctatin A (DotA), significantly reduced aflatoxin accumulation by repressing major genes of the aflatoxin biosynthesis pathway, afl ( $p k s A$ : polyketide synthase), aflM (ver-1: ketoreductase), and aflP (omtA: O-methyltransferase A), in A. parasiticus. DotA was found active in reducing biosynthesis of norsolorinic acid and sterigmatocystin, intermediate compounds in the aflatoxin biosynthesis pathway, but enhanced the biosynthesis of kojic acid (Yoshinari et al. 2007). In our study, genes from the kojic acid biosynthetic cluster were not significantly influenced by $V g$ treatments. Furukawa et al. (2020) reported that dioctatin precisely targets mitochondrial protease

AFLATOXIN BIOSYNTHESIS

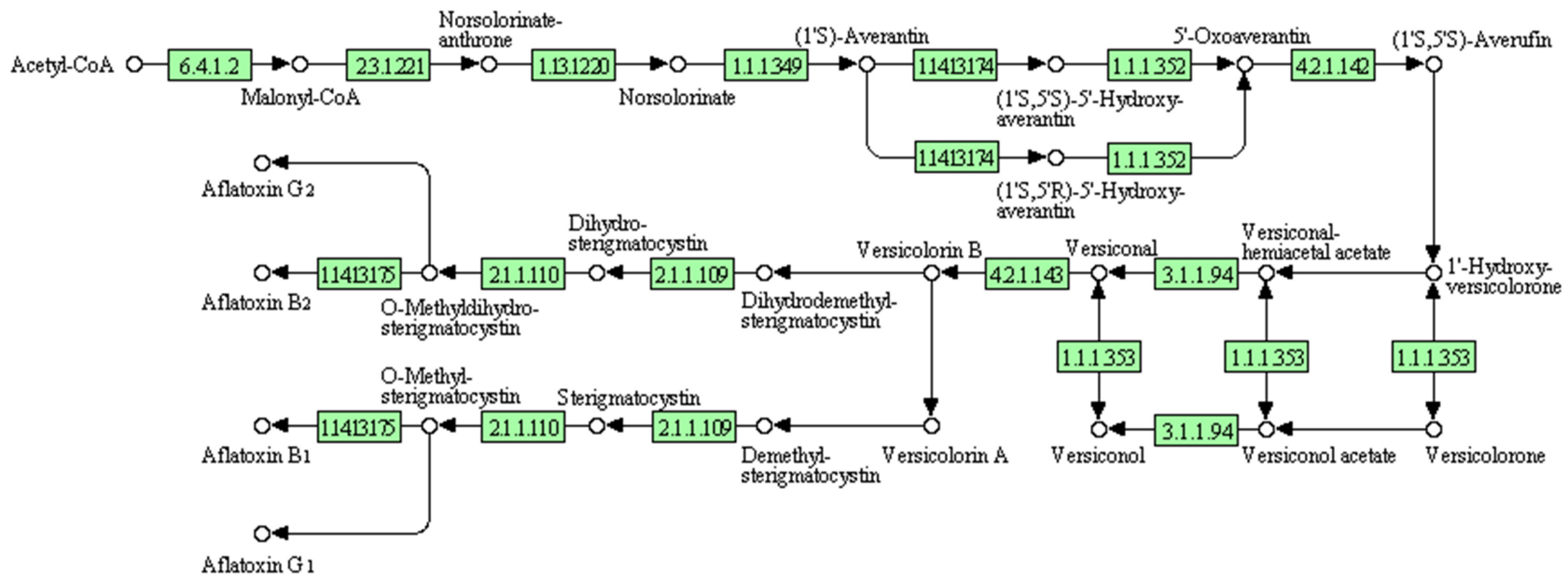

$0025410 / 21 / 13$

(c) Kanehisa Laboratories

\begin{tabular}{|c|c|c|c|c|c|}
\hline \multirow[t]{2}{*}{ KEGG Pathway term } & \multirow[t]{2}{*}{ DEGs with pathway annotation } & \multirow{2}{*}{\multicolumn{2}{|c|}{$\begin{array}{c}\text { Live vs Control } \\
\text { log2FoldChange padj }\end{array}$}} & \multicolumn{2}{|c|}{ Dead vs Control } \\
\hline & & & & $\log 2 \mathrm{FoldCh}$ & padj \\
\hline \multirow{10}{*}{ Aflatoxin biosynthesis } & AFLA_139190-aflK |vbs| VERB synthase & -9.98 & $5.0 \mathrm{E}-54$ & -3.74 & $1.9 \mathrm{E}-11$ \\
\hline & AFLA_139200-aflQ |ordA| oxidoreductase & -8.42 & $2.5 \mathrm{E}-34$ & -3.66 & $3.3 \mathrm{E}-10$ \\
\hline & AFLA_139210-afIP |omtA| O-methyltransferase A & -10.30 & 8.1E-44 & -3.78 & $3.2 \mathrm{E}-11$ \\
\hline & AFLA_139220-aflO |omtB| O-methyltransferase B & -10.48 & 3.4E-51 & -3.77 & $1.5 \mathrm{E}-11$ \\
\hline & AFLA_139260-aflG |avnA| cytochrome P450 monooxygenase & -9.71 & 1.7E-16 & -3.62 & $1.4 \mathrm{E}-04$ \\
\hline & AFLA_139320-aflJ |estA| esterase & -8.49 & 1.9E-29 & -3.85 & $5.3 \mathrm{E}-10$ \\
\hline & AFLA_139330-aflH |adhA| short chain alcohol dehydrogenase & -6.70 & 1.1E-18 & -3.61 & 2.3E-07 \\
\hline & AFLA_139390-afID |nor-1| reductase & -3.29 & 1.6E-10 & -2.65 & $1.4 \mathrm{E}-05$ \\
\hline & AFLA_139400-aflCa |hypC| hypothetical protein & -3.37 & 4.7E-12 & -2.64 & $1.9 \mathrm{E}-05$ \\
\hline & AFLA 139410 -aflC $\mid$ pksA| polyketide synthase & -2.50 & 1.7E-07 & -2.40 & $1.4 \mathrm{E}-04$ \\
\hline
\end{tabular}

\section{FIGURE 6}

Kyoto Encyclopedia of Genes and Genomes (KEGG) pathway of the aflatoxin biosynthesis in Aspergillus flavus. Downregulated genes (live or dead Vibrio gazogenes to untreated control comparisons) identified through KEGG pathway enrichment analysis and downregulated $\log _{2}$ fold change and corresponding adjusted $P$ value were provided. Downregulated genes linked with various enzymes involved in the aflatoxin biosynthesis pathway are displayed with a green background. DEGs = differentially expressed genes. 
ClpP and interferes with the mitochondrial energy metabolism process, which ultimately reduces aflatoxin production in A. flavus.

Previous studies have suggested that compounds antagonistic to aflatoxin biosynthesis have no substantial adverse effect on fungal growth (Sakuda et al. 2016), which is similar to our finding showing a statistically insignificant reduction in fungal biomass despite a significant inhibition in aflatoxin production upon treatment with $V g$. A recent study also showed that a significant reduction in aflatoxin production and downregulation of aflatoxin biosynthetic genes under co-cultivated conditions of A. flavus and Enterobacter cloacae. This finding is consistent with our observation of gene expression and aflatoxin production in A. flavus. However, a significant reduction in fungal growth was observed during co-cultivated conditions, unlike our results (Dong et al. 2020).

The weighted gene correlation network analysis identified gene modules with similar expression profiles, which were closely associated with $V g$-dependent aflatoxin inhibition. The majority of hub genes, especially in the turquoise and midnight blue modules, were found to be significantly upregulated at $40 \mathrm{~h}$ (live $V g$ versus untreated control). Genes in these modules were associated with extracellular cellulolytic and fatty acid hydrolytic activities such as cellulase, endoglucanase, lipase, and enoyl-CoA hydratase, indicating increased cell wall carbohydrate and fatty acid degradation mediated by A. flavus. Involvement of these enzymes in cellulose and fatty acid degradation was also observed in Aspergillus spp. as a means of producing and utilizing various organic substrates (Chandra et al. 2020; Julia et al. 2016; Liu et al. 2013; Maggio-Hall and Keller 2004). It is possible that $A$. flavus upregulates these enzymes in response to the extracellular polymeric substances (EPS) of $V g$. EPS is a diverse collection of carbohydrates, proteins, lipids, nucleic acids, and other heteropolymers produced by bacteria in aquatic environments including Vibrio spp. (Yildiz and Visick 2009; Ziemba et al. 2016). It is understood that the EPS on the bacterial surface helps it initiate the development of a biofilm by impacting the deposition characteristics such as charge and hydrophobicity or acting as a mechanical intermediary in attachment (Morgan et al. 1990; Tsuneda et al. 2003; Zhang and Bishop 2003). Furthermore, we also observed an upregulation of genes associated with siderophore biosynthesis and iron transport in Aspergillus spp. (Ecker et al. 2018; Robinson et al. 2021; Vob et al. 2020). It is possible that a portion of the iron in the growth medium binds to the Vibrio siderophores present in the EPS, reducing the iron concentration in the growth medium available for the fungus and triggering the fungus to upregulate its iron intake machinery. The associations between the $V g$-dependent aflatoxin inhibition and the upregulated hub genes will be investigated in our future studies. In addition, we observed significant upregulation in some ribosome-related genes, especially during the live $V g$ treatment at 30 and $40 \mathrm{~h}$. It is possible that $V g$ treatment influences the translational machinery in A. flavus to accommodate the cellular reprograming needed to alter the secondary metabolite profiles, an observation similar to a previous study in another fungal system (Cho et al. 2012).

Finally, in addition to aflatoxin genes, our analysis identified other secondary metabolite genes such as cyclopiazonic acid and aflavarin biosynthetic genes that were significantly downregulated. However, the effect of the treatments on the gene clusters of these secondary metabolites was not as drastic as the aflatoxin gene cluster. Although the observation suggests a possible specificity of the $V g$ treatments toward aflatoxin biosynthesis, it is possible that the effect on other secondary metabolite clusters could not be detected under the experimental and analytical methods used in the current study. Additionally, genes shown to be involved in global regulation of oxidative stress (atfB, $A P-1$ ) and secondary metabolism (veA, laeA, $n s d C$, and $n s d D$ ) were not significantly affected, especially at $40 \mathrm{~h}$, which supports our conclusion that inhibition appears to be highly specific to aflatoxin biosynthesis; however, the underlying mechanism of inhibition is yet to be determined. In future studies, we will investigate the mechanistic details of $V g$-dependent aflatoxin inhibition and whether the treatment can inhibit other secondary metabolites as well.

\section{LITERATURE CITED}

Adebo, O. A., Njobeh, P. B., and Mavumengwana, V. 2016. Degradation and detoxification of AFB1 by Staphylococcus warneri, Sporosarcina sp. and Lysinibacillus fusiformis. Food Control 68:92-96.

Alberts, J. F., Van Zyl, W. H., and Gelderblom, W. C. 2016. Biologically based methods for control of fumonisin-producing Fusarium species and reduction of the fumonisins. Front. Microbiol. 7:548.

Allen, G. R., Reichelt, J. L., and Gray, P. P. 1983. Influence of environmental factors and medium composition on Vibrio gazogenes growth and prodigiosin production. Appl. Environ. Microbiol. 45:1727-1732.

Al-Saad, L. A., Al-Badran, A. I., Al-Jumayli, S. A., Magan, N., and Rodriguez, A. 2016. Impact of bacterial biocontrol agents on aflatoxin biosynthetic genes, $a f D$ and aflR expression, and phenotypic aflatoxin B1 production by Aspergillus flavus under different environmental and nutritional regimes. Int. J. Food Microbiol. 217:123-129.

Benjamini, Y., and Hochberg, Y. 1995. Controlling the false discovery rate: A practical and powerful approach to multiple testing. J. R. Stat. Soc. Series B Stat. Methodol. 57:289-300.

Boric, M., Danevcic, T., and Stopar, D. 2011. Prodigiosin from Vibrio sp. DSM 14379; a new UV-protective pigment. Microb. Ecol. 62:528-536.

Brown, R. L., Menkir, A., Chen, Z. Y., Bhatnagar, D., Yu, J., Yao, H., and Cleveland, T. E. 2013. Breeding aflatoxin-resistant maize lines using recent advances in technologies-a review. Food Addit. Contam. Part A 30:13821391.

Bushnell, B. 2014. BBMap: A Fast, Accurate, Splice-Aware Aligner (No. LBNL-7065E). Lawrence Berkeley National Lab, Berkeley, CA.

Cary, J. W., Gilbert, M. K., Lebar, M. D., Majumdar, R., and Calvo, A. M. 2018. Aspergillus flavus secondary metabolites: More than just aflatoxins. Food Safety 6:7-32.

Cavalheiro, J., Zuloaga, O., Prieto, A., Preudhomme, H., Amouroux, D., and Monperrus, M. 2017. Occurrence and fate of organic and organometallic pollutants in municipal wastewater treatment plants and their impact on receiving waters (Adour Estuary, France). Arch. Environ. Contam. Toxicol. 73:619-630.

Chalivendra, S., DeRobertis, C., Reyes Pineda, J., Ham, J. H., and Damann, K. 2018. Rice phyllosphere Bacillus species and their secreted metabolites suppress Aspergillus flavus growth and aflatoxin production in vitro and in maize seeds. Toxins 10:159.

Chalivendra, S., and Ham, J. H. 2019. Bacilli in the biocontrol of mycotoxins. Pages 49-62 in: Bacilli and Agrobiotechnology: Phytostimulation and Biocontrol, Bacilli in Climate Resilient Agriculture and Bioprospecting. M.T. Islam, M. M. Rahman, P. Pandey, M. H. Boehme, and G. Haesaert, eds. Springer International, Cham, Switzerland.

Chandra, P., Singh, R., and Arora, P. K. 2020. Microbial lipases and their industrial applications: A comprehensive review. Microb. Cell Fact. 19: $1-42$.

Cho, W. K., Yu, J., Lee, K. M., Son, M., Min, K., Lee, Y. W., and Kim, K. H. 2012. Genome-wide expression profiling shows transcriptional reprogramming in Fusarium graminearum by Fusarium graminearum virus 1-DK21 infection. BMC Genomics 13:1-16.

de Matos Simoes, R., and Emmert-Streib, F. 2012. Bagging statistical network inference from large-scale gene expression data. PLoS One 7:e33624.

Dobin, A., Davis, C. A., Schlesinger, F., Drenkow, J., Zaleski, C., Jha, S., Batut, P., Chaisson, M., and Gingeras, T. R. 2013. STAR: Ultrafast universal RNA-seq aligner. Bioinformatics 29:15-21.

Dong, X., Zhang, Q., Zhang, Z., Yue, X., Zhang, L., Chen, X., Zhang, W., Chen, L., and Li, P. 2020. Inhibitory effect of Enterobacter cloacae 3J1EC on Aspergillus flavus 3.4408 growth and aflatoxin production. World Mycotoxin J. 13:259-266.

Drott, M. T., Rush, T. A., Satterlee, T. R., Giannone, R. J., Abraham, P. E., Greco, C., Venkatesh, N., Skerker, J. M., Glass, N. L., Labbe, J. L., and Milgroom, M. G. 2021. Microevolution in the pansecondary metabolome of Aspergillus flavus and its potential macroevolutionary implications for filamentous fungi. Proc. Natl Acad. Sci. 118:e2021683118. 
Ecker, F., Haas, H., Groll, M., and Huber, E. M. 2018. Iron scavenging in Aspergillus species: Structural and biochemical insights into fungal siderophore esterases. Angew. Chem. Int. Ed. 57:14624-14629.

Furukawa, T., Katayama, H., Oikawa, A., Negishi, L., Ichikawa, T., Suzuki, M., Murase, K., Takayama, S., and Sakuda, S. 2020. Dioctatin activates ClpP to degrade mitochondrial components and inhibits aflatoxin production. Cell Chem. Biol. 27:1396-1409.

Gong, A. D., Li, H. P., Yuan, Q. S., Song, X. S., Yao, W., He, W. J., Zhang, J. B., and Liao, Y. C. 2015. Antagonistic mechanism of iturin A and plipastatin A from Bacillus amyloliquefaciens S76-3 from wheat spikes against Fusarium graminearum. PLoS One 10:e0116871.

Gu, Z., Eils, R., and Schlesner, M. 2016. Complex heatmaps reveal patterns and correlations in multidimensional genomic data. Bioinformatics 32:2847-2849.

Gummadidala, P. M. 2018. Inhibition of aflatoxin biosynthesis with Vibrio gazogenes. Doctoral dissertation, University of South Carolina, Columbia, $\mathrm{SC}$.

Gummadidala, P. M., Chen, Y. P., Beauchesne, K. R., Miller, K. P., Mitra, C., Banaszek, N., Velez-Martinez, M., Moeller, P. D., Ferry, J. L., Decho, A. W., and Chanda, A. 2016. Aflatoxin-exposure of Vibrio gazogenes as a novel system for the generation of aflatoxin synthesis inhibitors. Front. Microbiol. 7:814.

Gummadidala, P. M., Holder, M. E., O’Brien, J. L., Ajami, N. J., Petrosino, J. F., Mitra, C., Chen, Y. P., Decho, A. W., and Chanda, A. 2017. Complete genome sequence of Vibrio gazogenes ATCC 43942. Genome Announc. 5:e00733-17.

Han, R., Xiang, R., Li, J., Wang, F., and Wang, C. 2021. High-level production of microbial prodigiosin: A review. J. Basic Microbiol. 61: 506-523.

Hua, S. S. T., Sarreal, S. B. L., Chang, P. K., and Yu, J. 2019. Transcriptional regulation of aflatoxin biosynthesis and conidiation in Aspergillus flavus by Wickerhamomyces anomalus WRL-076 for reduction of aflatoxin contamination. Toxins 11:81.

Hyde, K. D., Al-Hatmi, A. M., Andersen, B., Boekhout, T., Buzina, W., Dawson, T. L., Eastwood, D. C., Jones, E. G., de Hoog, S., Kang, Y., and Longcore, J. E. 2018. The world's ten most feared fungi. Fungal Divers. 93:161-194.

IARC. 1993. Some naturally occurring substances: Food items and constituents, heterocyclic aromatic amines and mycotoxins. Pages 397-444 in: IARC Monographs on the Evaluation of Carcinogenic Risks to Humans, vol. 56. International Agency for Research on Cancer, Lyon, France.

Jesmin, R. 2020. Mechanistic insight on Vibrio gazogenes mediated intervention of aflatoxin biosynthesis in Aspergillus flavus. Doctoral dissertation, University of South Carolina, Columbia, SC.

Julia, B. M., Belen, A. M., Georgina, B., and Beatriz, F. 2016. Potential use of soybean hulls and wastepaper as supports in SSF for cellulase production by Aspergillus niger. Biocatal. Agric. Biotechnol. 6:1-8.

Kanehisa, M., and Goto, S. 2000. KEGG: Kyoto Encyclopedia of Genes and Genomes. Nucleic. Acids. Res. 28:27-30.

Kanehisa, M., Sato, Y., Furumichi, M., Morishima, K., and Tanabe, M. 2019. New approach for understanding genome variations in KEGG. Nucleic. Acids. Res. 47:D590-D595.

Kenne, G.J., Gummadidala, P. M., Omebeyinje, M. H., Mondal, A. M., Bett, D. K., Mcfadden, S., Bromfield, S., Banaszek, N., Velez-Martinez, M., Mitra, C., Mikell, I., Chatterjee, S., Wee, J., and Chanda, A. 2018. Activation of aflatoxin biosynthesis alleviates total ROS in Aspergillus parasiticus. Toxins 10:57.

Kong, Q., Chi, C., Yu, J., Shan, S., Li, Q., Li, Q., Guan, B., Nierman, W. C., and Bennett, J. W. 2014. The inhibitory effect of Bacillus megaterium on aflatoxin and cyclopiazonic acid biosynthetic pathway gene expression in Aspergillus flavus. Appl. Microbiol. Biotechnol. 98:5161-5172.

Langfelder, P., and Horvath, S. 2008. WGCNA: An R package for weighted correlation network analysis. BMC Bioinf. 9:1-13.

Legein, M., Smets, W., Vandenheuvel, D., Eilers, T., Muyshondt, B., Prinsen, E., Samson, R., and Lebeer, S. 2020. Modes of action of microbial biocontrol in the phyllosphere. Front. Microbiol. 11:1619.

Liao, J., He, Z., Xia, Y., Lei, Y., and Liao, B. 2020. A review on biosynthesis and genetic regulation of aflatoxin production by major Aspergillus fungi. Oil Crop Sci. 5:166-173.

Liao, Y., Smyth, G. K., and Shi, W. 2014. featureCounts: An efficient general purpose program for assigning sequence reads to genomic features. Bioinformatics 30:923-930.

Liu, D., Li, J., Zhao, S., Zhang, R., Wang, M., Miao, Y., Shen, Y., and Shen, Q. 2013. Secretome diversity and quantitative analysis of cellulolytic Aspergillus fumigatus $\mathrm{Z} 5$ in the presence of different carbon sources. Biotechnol. Biofuels. 6:1-16.

Love, M. I., Huber, W., and Anders, S. 2014. Moderated estimation of fold change and dispersion for RNA-seq data with DESeq2. Genome Biol. $15: 1-21$.
Maggio-Hall, L. A., and Keller, N. P. 2004. Mitochondrial $\beta$-oxidation in Aspergillus nidulans. Mol. Microbiol. 54:1173-1185.

Majumdar, R., Lebar, M., Mack, B., Minocha, R., Minocha, S., CarterWientjes, C., Sickler, C., Rajasekaran, K., and Cary, J. W. 2018. The Aspergillus flavus Spermidine synthase (spds) gene, is required for normal development, aflatoxin production, and pathogenesis during infection of maize kernels. Front. Plant Sci. 9:317.

Morgan, J. W., Forster, C. F., and Evison, L. 1990. A comparative study of the nature of biopolymers extracted from anaerobic and activated sludges. Water Res. 24:743-750.

Nelson, R. 2016. Sorting technologies to rehabilitate toxic maize. Outlooks Pest Manag. 27:247-251.

Nicholson, M. J., Koulman, A., Monahan, B. J., Pritchard, B. L., Payne, G. A., and Scott, B. 2009. Identification of two aflatrem biosynthesis gene loci in Aspergillus flavus and metabolic engineering of Penicillium paxilli to elucidate their function. Appl. Environ. Microbiol. 75:7469-7481.

Ojiambo, P. S., Battilani, P., Cary, J. W., Blum, B. H., and Carbone, I. 2018 Cultural and genetic approaches to manage aflatoxin contamination: Recent insights provide opportunities for improved control. Phytopathology 108:1024-1037.

Osterholz, H., Kirchman, D. L., Niggemann, J., and Dittmar, T. 2018. Diversity of bacterial communities and dissolved organic matter in a temperate estuary. FEMS Microbiol. Ecol. 94:fiy119.

Palazzini, J. M., Dunlap, C. A., Bowman, M. J., and Chulze, S. N. 2016. Bacillus velezensis RC 218 as a biocontrol agent to reduce Fusarium head blight and deoxynivalenol accumulation: Genome sequencing and secondary metabolite cluster profiles. Microbiol. Res. 192:30-36.

Pickova, D., Ostry, V., Toman, J., and Malir, F. 2021. Aflatoxins: History, significant milestones, recent data on their toxicity and ways to mitigation. Toxins 13:399.

R Core Team 2020. The R project for statistical computing, Vienna, Austria. Available at: http://www.R-project.org/

Rao, K. R., Vipin, A. V., Hariprasad, P., Appaiah, K. A., and Venkateswaran, G. J. F. C. 2017. Biological detoxification of Aflatoxin B1 by Bacillus licheniformis CFR1. Food Control 71:234-241.

Robinson, J. R., Isikhuemhen, O. S., and Anike, F. N. 2021. Fungal-metal interactions: A review of toxicity and homeostasis. J. Fungus 7:225.

Sakuda, S. 2010. Mycotoxin production inhibitors from natural products. Mycotoxins 60:79-86.

Sakuda, S., Ikeda, H., Nakamura, T., Kawachi, R., Kondo, T., Ono, M., Sakurada, M., Inagaki, H., Ito, R., and Nagasawa, H. 2000. Blasticidin A derivatives with highly specific inhibitory activity toward aflatoxin production in Aspergillus parasiticus. J. Antibiot. Res. 53:1378-1384.

Sakuda, S., Ono, M., Furihata, K., Nakayama, J., Suzuki, A., and Isogai, A. 1996. Aflastatin A, a novel inhibitor of aflatoxin production of Aspergillus parasiticus, from Streptomyces. J. Am. Chem. Soc. 118:7855-7856.

Sakuda, S., Yoshinari, T., Furukawa, T., Jermnak, U., Takagi, K., Iimura, K., Yamamoto, T., Suzuki, M., and Nagasawa, H. 2016. Search for aflatoxin and trichothecene production inhibitors and analysis of their modes of action. Biosci. Biotechnol. 80:43-54.

Seshime, Y., Juvvadi, P. R., Tokuoka, M., Koyama, Y., Kitamoto, K., Ebizuka, Y., and Fujii, I. 2009. Functional expression of the Aspergillus flavus PKSNRPS hybrid CpaA involved in the biosynthesis of cyclopiazonic acid. Bioorganic Med. Chem. Lett. 19:3288-3292.

Shu, X., Wang, Y., Zhou, Q., Li, M., Hu, H., Ma, Y., Chen, X., Ni, J., Zhao, W., Huang, S., and Wu, L. 2018. Biological degradation of aflatoxin B1 by cell-free extracts of Bacillus velezensis DY3108 with broad PH stability and excellent thermostability. Toxins 10:330.

Smith, J. S., Williams, W. P., and Windham, G. L. 2019. Aflatoxin in maize: A review of the early literature from "moldy-corn toxicosis" to the genetics of aflatoxin accumulation resistance. Mycotoxin Res. 35:111-128.

Tsuneda, S., Aikawa, H., Hayashi, H., Yuasa, A., and Hirata, A. 2003. Extracellular polymeric substances responsible for bacterial adhesion onto solid surface. FEMS Microbiol. Lett. 223:287-292.

Uka, V., Cary, J. W., Lebar, M. D., Puel, O., De Saeger, S., and Diana Di Mavungu, J. 2020. Chemical repertoire and biosynthetic machinery of the Aspergillus flavus secondary metabolome: A review. Compr. Rev. Food Sci. Food Saf. 19:2797-2842.

USDA-NASS. 2021. Agricultural Statistics 2021. Available at: https://www nass.usda.gov/. USDA-NASS, Washington, DC.

Veliz, E. A., Martinez-Hidalgo, P., and Hirsch, A. M. 2017. Chitinaseproducing bacteria and their role in biocontrol. AIMS Microbiol. 3:689.

Vob, B., Kirschhofer, F., Brenner-Weib, G., and Fischer, R. 2020. Alternaria alternata uses two siderophore systems for iron acquisition. Sci. Rep. 10:1-10.

Wickham, H. 2016. ggplot2-Elegant Graphics for Data Analysis. SpringerVerlag, New York. Available at: https://ggplot2.tidyverse.org

Williams, J. H., Phillips, T. D., Jolly, P. E., Stiles, J. K., Jolly, C. M., and Aggarwal, D. 2004. Human aflatoxicosis in developing countries: A review 
of toxicology, exposure, potential health consequences, and interventions. Am. J. Clin. Nutr. 80:1106-1122.

World Health Organization (WHO) Aflatoxins. Food Safety Digest, Department of Food safety and Zoonoses. REF. No.: WHO/NHM/FOS/RAM/ 18.1. 2018. Available at: https://www.who.int/foodsafety/FSDigest_ Aflatoxins_EN.pdf. Accessed January 6, 2019.

Xia, X., Zhang, Y., Li, M., Garba, B., Zhang, Q., Wang, Y., Zhang, H., and $\mathrm{Li}, \mathrm{P} .2017$. Isolation and characterization of a Bacillus subtilis strain with aflatoxin B1 biodegradation capability. Food Control 75:92-98.

Xie, C., Mao, X., Huang, J., Ding, Y., Wu, J., Dong, S., Kong, L., Gao, G., Li, C.Y., and Wei, L. 2011. KOBAS 2.0: a web server for annotation and identification of enriched pathways and diseases. Nucleic acids Res. 39:W316-W322.

Xie, Y., Wang, W., and Zhang, S. 2019. Purification and identification of an aflatoxin B1 degradation enzyme from Pantoea sp. T6. Toxicon 157:35-42.

Yildiz, F. H., and Visick, K. L. 2009. Vibrio biofilms: So much the same yet so different. Trends Microbiol. 17:109-118.
Yoshinari, T., Akiyama, T., Nakamura, K., Kondo, T., Takahashi, Y., Muraoka, Y., Nonomura, Y., Nagasawa, H., and Sakuda, S. 2007. Dioctatin A is a strong inhibitor of aflatoxin production by Aspergillus parasiticus. Microbiology 153:2774-2780.

Young, M. D., Wakefield, M. J., Smyth, G. K., and Oshlack, A. 2010. Gene ontology analysis for RNA-seq: Accounting for selection bias. Genome Biol. 11:1-12

Yu, J. 2012. Current understanding on aflatoxin biosynthesis and future perspective in reducing aflatoxin contamination. Toxins 4:1024-1057.

Zhang, S., Hu, Z., and Wang, H. 2019. Metagenomic analysis exhibited the cometabolism of polycyclic aromatic hydrocarbons by bacterial community from estuarine sediment. Environ. Int. 129:308-319.

Zhang, X., and Bishop, P. L. 2003. Biodegradability of biofilm extracellular polymeric substances. Chemosphere 50:63-69.

Ziemba, C., Shabtai, Y., Piatkovsky, M., and Herzberg, M. 2016. Cellulose effects on morphology and elasticity of Vibrio fischeri biofilms. NPJ Biofilms Microbiomes 2:1-9. 